\title{
The Romani Archives and Documentation Center: A Migratory Archive?
}

\section{Mariana Sabino Salazar}

soymariana@gmail.com

PhD candidate and Instructor of Record at the University of Texas at Austin

ORCID: https://orcid.org/0000-0003-4580-2341

Mariana Sabino Salazar is a $\mathrm{PhD}$ candidate in Iberian and Latin American Literatures and Cultures. Her dissertation is about the perpetuation of the Iberian "Gypsy" femme fatale literary archetype in Brazilian and Mexican cinema between 1950 and 1980. Her research interests include counter-archives, subaltern history, stereotypes and prejudice, and gender and nationalism. She volunteered at the Romani Archives and Documentation Center from 2013 to 2019 and has published two book chapters related to Romani history in Latin America.

\section{Critical}

Romani Studies 


\section{Abstract}

The purpose of this review is to outline the history of the Romani Archives and Documentation Center (RADOC), its origin, mission, function, and what sets it apart from other archives in the world. Ian Hancock, emeritus professor at the University of Texas at Austin (UT) and author of The Pariah Syndrome (1987) and We Are the Romani People (2002), initiated the collection and was responsible for its organization and preservation for the last 50 years. Due to Hancock's recent retirement, RADOC will soon move from Texas to Turkey. It seems appropriate to reflect on this unique collection through Rodrigo Lazo's concept of the migratory archive. RADOC differs from hegemonic national archives because it represents a heterogeneous group of people dispersed throughout the world who speak different languages. Romani history has been largely written by outsiders, but the experience of Roma has also been recorded through other means, including literature and music. Regardless of the format, RADOC is committed to preserving the diversity of Romani voices. It is crucial that new generations of Romani and nonRomani scholars fight for the conservation of this archive and the preservation of Romani history.

\section{Keywords}

- Ian Hancock

- History

- Literature

- Migratory archives

- National archives 


\section{What is RADOC?}

The Romani Archives and Documentation Center (RADOC) is a collection initiated by Ian Hancock more than 50 years ago. RADOC became one of the most important Romani archives in the world and is now in a process of reconfiguration. It is made up of over 10,000 pieces of printed materials, including books, monographs, articles, periodicals, and dissertations. The collection also contains audio and visual recordings in different formats (DVDs, tapes, compact discs, photographs, and transparencies), as well as maps, posters, prints, and artifacts. The documentation relates to Romani organizations and educational project reports in the United States and Europe. It has been housed in Calhoun Hall at the University of Texas at Austin (UT) for the last 45 years. At Calhoun Hall, RADOC was open by appointment for academic research and served patrons from around the world.

RADOC was a counterpart of the Croft-Cooke Collection hosted by the Harry Ransom Center, which is located only a few steps away from Calhoun Hall. The Croft-Cooke Collection is focused on European Roma and contains the correspondence and collection of Rupert Croft-Cooke, a prominent member of the Gypsy Lore Society ${ }^{[1]}$ RADOC, on the other hand, was established by Hancock, a Romani intellectual, to reflect on the diversity of the Romani experience throughout the world. One of RADOC's main objectives is to contest the stereotype of the "Gypsy" by preserving the cultural products that have facilitated the circulation of this image. Over the years, RADOC's volunteers have been responsible for documenting racist media portrayals and legislation, and monitoring publishers, advertisers, and television producers. For the last five years, RADOC has also served as a meeting point and research space for Romani students and scholars in the field of Romani Studies at UT. It currently functions as a small cultural center that organizes the "Barvale Sam (We Are Rich!)”: The Wealth of Romani Lifeworlds film series and promotes other cultural activities. ${ }^{[2]}$

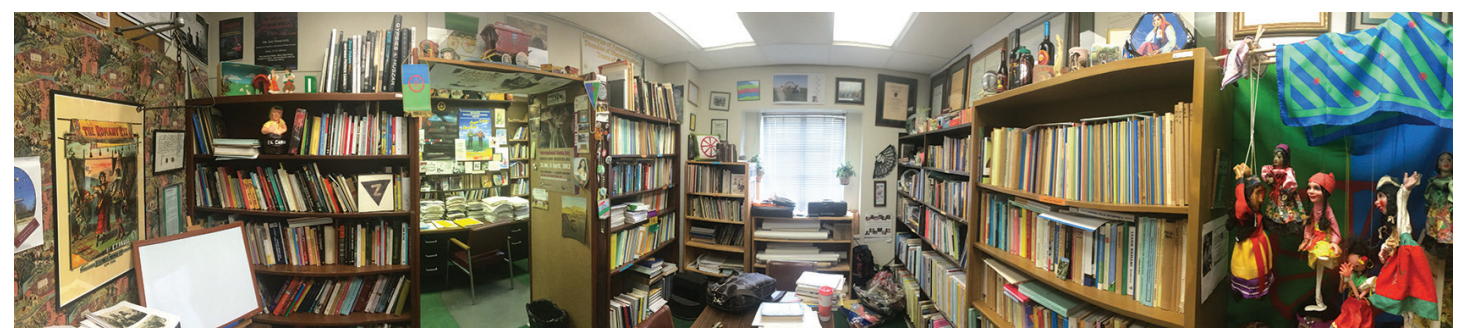

RADOC was housed in a two-room office. In the first room was Prof. Hancock's office, the video, image, and newspaper collection, and the reference section that included country by country modules. In the second room, there was a meeting room, the music and linguistic collections, and other thematic sections such as law, women, performing arts, education, and so on. The picture was taken from the second room. On the right side, there is the marionette collection.

1 Rupert Croft-Cooke was the author of The Moon in My Pocket: Life with the Romanies (1948) and A Few Gypsies (1955). He was very prolific and wrote books in multiple genres, among them 31 detective novels under the pseudonym Leo Bruce. Other books he published related to "Gypsies" and the circus were Pharaoh with His Wagons (1937), Case with Four Clowns (1939), and The Circus Has No Home (1941). See Evans 2010.

2 Among those cultural activities RADOC promotes, there have been two exhibits. Romanies in Texas was held in the Bullock Texas State History Museum in Austin, from June 2017 to June 2018, and The Myth of the Gypsy Femme Fatale was exhibited at the Perry-Castañeda Library at UT from February 2020 to August 2020. 


\section{Ian Hancock and RADOC}

Hancock first took an interest in researching the history of Romani people when he was a student at the University of London. He started collecting materials during the 1960s, a decade when many important counterculture movements originated. His desire to learn and become part of a group that shared his views led him to meet Thomas Acton, Donald Kenrick, and Grattan Puxton, all of whom were part of the National Gypsy Education Council in East London.

Hancock's interest in establishing a collection of materials portraying Romani/Gypsies intensified at the 1971 World Romani Congress. The emergence of Romani national consciousness movements led to a proliferation of Romani scholars and political leaders interested in combating xenophobia. Among them were Ronald Lee, Rajko Đurić, Juan de Dios Ramírez Heredia, and Hancock. During this congress, the Romani flag and anthem were adopted. These symbols proclaimed a set of ideas collectively known as Romani nationalism (Gelbart, n.d.). While there were a few renowned European Romani writers, Romani history had yet to be written by Roma themselves. Hancock's objective was to collect historic evidence of the Romani people that contrasted with the romantic stereotype of the wandering Gypsy. Unknowingly, he was establishing a kind of national archive that gave legitimacy and credibility to the Romani nationalist project. Hancock realized that archives constitute the memory of nations and societies, and that it was important to examine who produced and controlled the information related to "Gypsies" and Roma.

Hancock's life became intertwined with that of RADOC; he spent his life as its curator and head archivist. When Hancock was appointed assistant professor at UT in 1972, he began to slowly ship the collection from London and Canada to Austin. At this point, the collection was a growing archive of the books acquired and collected throughout Hancock's life. Hancock would often make xeroxed copies of books that were not for sale in a printed edition and add these to the archive. He would also carefully bind those materials using paperboard and tape, sometimes even hand-stitching the pages together. Some friends and scholars donated part of their collections, as was the case with the activist Donald Kenrick, writer Diane Tong, and anthropologist William G. Lockwood. ${ }^{[3]}$ Other organizations, publishers, and individuals contributed throughout the years with other materials - mostly books and journals.

In many ways, the archive's early history ran parallel with Hancock's career as an academic and activist. He was promoted to professor in 1984 and used the bonus he was granted to buy materials for RADOC. Hancock's collection reflects the topics in which he was particularly interested, encompassing linguistics, the Romani victims of the Holocaust, and the history of Roma enslavement in Wallachia and Moldavia. The collection also includes a number of Hancock's own writings and teaching materials, along with different versions and manuscripts, which provide insights into his thinking at the time.

3 Lockwood was a professor at the University of Michigan from 1969 to 1997. He contributed to RADOC before his death in 2017. In 2016, the William G. Lockwood Collection of Romani Ethnology and Gypsy Stereotypes at Michigan State University was established. The collection, donated by Lockwood and curated by his wife, Yvonne, contains several thousand items focused on the Balkans, Romani/Gypsy culture, ethnicity, and the anthropology of food and foodways. 
Hancock's appointment to the U.S. Holocaust Memorial Council promised to transform RADOC into an educational project. The Council drafted a proposal that led to the establishment of the United Romani Educational Foundation in 2001. ${ }^{[4]}$ The Foundation was intended to be funded from the compensation for looted Swiss assets seized from Sinti, Manouche, and Roma Holocaust victims after their arrest. The plan was to develop a network of cultural centers equipped with libraries and Internet access for promoting Romani scholarship and academic activities. Although the funds never became available, RADOC still aimed to function as an educational entity serving Romani people. In 2018, Hancock retired as a professor in the departments of Linguistics and English at UT. He was able to negotiate with UT for the archive to be held in its original premises for one year after his retirement, but in 2019, RADOC closed its doors. Years before, Hancock had approached and been approached by European and American institutions interested in acquiring RADOC. Hancock's most important condition was that the institution that purchased the collection needed to launch a Romani research center in parallel so that the materials in the collection would serve the purpose of expanding Romani research in different fields.

\section{RADOC's Future}

In 2018, Hancock decided to allow a group of Romani intellectuals and activists to take over the operation of RADOC's educational project. Initially, Orhan Galhus and Hristo Kyuchukov offered to provide a new home for the collection in Turkey, possibly in the national archives in Istanbul. ${ }^{[5]}$ Turkey's geographic location as a transcontinental state between Europe and Asia made it more accessible to the largest Romani communities. It is also an important space for understanding Romani history, given that Anatolia might be the place where Romani identity once formed. ${ }^{[6]}$ In the last year, Hancock has considered offers from the Museum of Civilizations of Europe and the Mediterranean (MuCEM) and a Canadian university. As for now, RADOC has not been relocated and Hancock is still looking for an institution to host the collection in an attempt to renew its legacy as an archive that preserves Romani history for future generations of Roma and non-Roma.

\section{RADOC as a Migratory Archive}

For Rodrigo Lazo, a migrant archive "reside[s] in obscurity and is always at the edge of annihilation" (Lazo 2010, 37). "Migratory archives are not widely available, nor is their existence known by a large number of people" (Ibid., 50). Lazo's notion of a migratory archive is oxymoronic: while the purpose of any archive is to safeguard historic knowledge, the texts in a migratory archive cross borders, jeopardizing their integrity and putting the archive at risk (Ibid., 38). Although Lazo used the concept of a "migrant archive"

4 This proposal was drafted by the Council, headed by U.S. Attorney General Ramsey Clark and Michael Rubenstein, and consisting of seventeen members, Hancock being the chairman.

5 The Ottoman Archives at the Başbakanlık Osmanlı Arşivleri (the Prime Minister's Ottoman Archives) in the Kâğıthane district, Istanbul.

6 According to Adrian Marsh, the first reference to Roma people - who were difficult to distinguish from Lom or the Atsinganoi dates back to the eleventh century (Marsh 2010, 27). Their presence was well-documented from the twelfth century on. They were an important part of Ottoman society and joined the forces who took Constantinople in 1453 (Ibid., 28). 


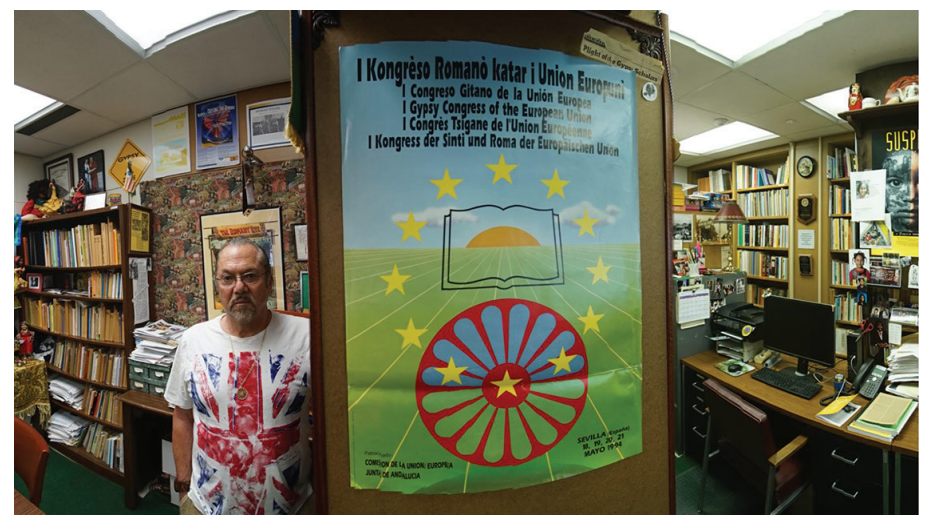

Prof. Ian Hancock in RADOC prior to its closure.

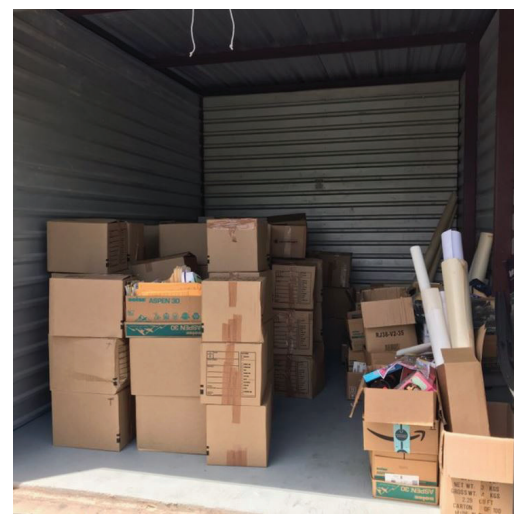

Some of the boxes that include the collection in a storage facility awaiting their next location.

to understand the place of (Hispanic) subaltern voices within the Anglo-American nation, his ideas are relevant to the study of RADOC. Like the migrant archives Lazo describes, RADOC is a transcultural project that represents a heterogeneous and multilingual group of people. It contains texts that challenge official narratives and deviate from those typically found in official narratives and standardized languages.

RADOC has no official language and includes materials in more than 40 different ones. Although RADOC was initially comprised of texts in hegemonic languages like English, French, Italian, and German, it now features texts in Romani and other less prominent languages such as Albanian, Japanese, Finnish, and Slovak. The archive documents different Romani dialects through dictionaries and samples, directly impacting the conservation of Romani voices. For Lazo, writing in another language "can lead scholars to alternative ways of remembering the past, new ways of naming multiple nations and communities, and even the invention of new ontologies" (Ibid., 38). One of RADOC's core missions is to show the difference between the myth of the Gypsy and the reality of Roma, and the adequacy of using endonyms and exonyms. This mission has contributed to the formation of a pan-Romani political identity. RADOC is a collection that speaks to a common legacy, even if that legacy is a history of persecution and trauma. The collection gives physical credibility to the Romani national project, as it implies continuity and tradition.

\section{Cataloguing Criteria}

RADOC grew more diverse over the years, challenging the limits of cataloging systems. One of RADOC's largest sub-collections is devoted to the preservation of Romani literature, and it contains a wide array of works by Romani authors, including different editions, translations, and even autographed copies. While traditional archives would host published materials edited by "reputable" sources, RADOC accommodates texts that otherwise would be destroyed. The inclusion of materials that represent Romani polyvocality also affects cataloging criteria. For example, most established archives contain defined history and literature categories, but in the Romani archives these two intersect. In this sense, RADOC supports the legitimization of other forms of history, such as stories, poems, and songs. 
Although literature does not follow positivistic historical methods, it is a device to preserve and communicate history itself. ${ }^{[7]}$ For Roma, literature is valuable as a testimonial tool for recording memories and lived experiences that recount trauma and resistance. It also represents a receptacle of diverse Romani cultural backgrounds, customs, and traditions. Bronisława Wajs' poems and Matéo Maximoff's novels, for example, document their perspective and position in the matrix of power. Literary practices (from poetry and theater to the performing and visual arts) have delineated Romani cultural and political identities and have been instrumental in the creation of a historical narrative.

\section{Conclusion}

Romani history has been overwhelmingly written by outsiders because it is a challenging and expensive task that few can undertake. Even the most important archives and libraries have small collections of materials related to the history of Roma or the Gypsy stereotype. In order to contrast the information found in a few books, a rigorous social scientist would have to travel to other locations and latitudes to research in other small collections. RADOC democratizes this effort by making available various documents scattered throughout hundreds of libraries and archives around the world. There has been a tendency to digitize the most important repositories of archival materials in the world, but that should not replace the actual physical collection. Digital archives move beyond a fixed location, but they are fragile and prone to disappear. Even if RADOC is eventually digitized, Romani organizations should be held responsible for the preservation of the physical archive.

RADOC's history allows us to reflect on who has access to Romani archives, what their cultural and national identity is, and who controls this information. RADOC was the first Romani archive in which the leadership roles were occupied by Roma, a model that other successful digital collections like RomArchive and the European Roma Institute of Arts and Culture have imitated. RADOC also distances itself from the notion of a single-language archive by showcasing the multilingual and heterogenous past of Romani. The preservation of this collection is fundamental to safeguarding the history and legacy of Roma. It is important that the new generation of Roma activists and academics understand the responsibility they are inheriting and are equipped to make decisions regarding the future of the collection.

7 The relationship between literature and history has been studied by numerous scholars, from Aristotle in his Poetics to Michel Foucault in The Order of Things. 


\section{References}

Acton, Thomas. 1988. "A Report on the Situation of Roma in the United States, c.1988." RomArchive, 24 February. https://www.romarchive.eu/en/collection/report-on-the-situation-of-roma-in-the-united-states-c1988

Evans, Curt. 2010. “The Man Who Was Leo Bruce” American Culture, 13 November. http://theamericanculture.org/the-man-who-was-leo-bruce

Gelbart, Petra. n.d. “The Romani Anthem as a Microcosm of Diversity." RomArchive. https://www.romarchive.eu/en/music/romani-anthem-microcosm-diversity

Hancock, Ian. 2020. Interview by the author. Digitally recorded. Austin, TX, 30 January.

International Council on Archives (ICA). 2016. "Mission, Aim and Objectives." Last modified 29 January 2020. https://www.ica.org/en/mission-aim-and-objectives

Lazo, Rodrigo. 2010. "Migrant Archives: New Routes in and out of American Studies." In Teaching and Studying the Americas, edited by Anthony B. Pinn, Caroline F. Levander, and Michael O. Emerson, 199-217. New York: Palgrave Macmillan. https://doi.org/10.1057/9780230114432_11

Marsh, Adrian. 2010. “The Gypsies in Turkey." In All Change!: Romani Studies through Romani Eyes, edited by Damian Le Bas and Thomas Acton, 27-38. Hertfordshire, UK: Hertfordshire Press.

Romani Archives and Documentation Center (RADOC). 2007. “About RADOC.” Accessed 10 February 2020. https://www.radoc.net 